C2017, Elsevier. Licensed under the Creative Commons Attribution-NonCommercialNoDerivatives 4.0 International http://creativecommons.org/about/downloads c) $($ ) $९ \bigcirc$ 


\title{
The Metacognitions about Self-Critical Rumination Questionnaire
}

\author{
Regular Article \\ Word count: 9713 \\ Date of submission: 02/11/2016 \\ Date of second submission: 16/02/2017 \\ Date of third submission: 22/04/2017
}

Daniel C. Kolubinski ${ }^{\mathrm{a}}$, Ana V. Nikčević ${ }^{\mathrm{b}}$, Jacqueline A. Lawrence ${ }^{\mathrm{a}}$, and Marcantonio M. Spada ${ }^{\text {a,* }}$

${ }^{a}$ Division of Psychology, School of Applied Sciences, London South Bank University, London, UK

${ }^{\mathrm{b}}$ Department of Psychology, Kingston University, Kingston upon Thames, UK

*Correspondence to: Professor Marcantonio Spada, Division of Psychology, School of Applied Sciences, London South Bank University, London, United Kingdom. Tel. +44 (0)20 7815 7815, e-mail spadam@1sbu.ac.uk. 


\section{Abstract}

Background: Self-criticism refers to a series of persistent and negative self-judgements, often involuntary, that an individual makes about themselves. Recent research has explored the possibility that self-criticism can lead to a more perseverative style of thinking called selfcritical rumination. There is evidence that self-critical rumination may be a separate construct from other forms of rumination, such as depressive rumination and post-event processing. Research has indicated that metacognitions, beliefs that individuals have about their internal experiences and how to control them, may play a role in self-critical rumination. The aim of our work was to develop a measure to assess metacognitions related to self-critical rumination. Method: In Study 1, a community sample of 178 participants completed the newly developed Metacognitions about Self-Critical Rumination Questionnaire (MSCRQ) and results were subjected to a Principal Components Analysis. In Study 2, a community sample of 247 participants completed a battery of questionnaires including the MSCRQ. A Confirmatory Factors Analysis was performed on the MSCRQ and validity was ascertained by correlating with other measures. Results: In Study 1, a 15-item two-factor structure was identified. A 10-item two-factor structure was confirmed in Study 2. Results also indicated that the MSCRQ has acceptable levels of reliability, and good concurrent and incremental validity. Conclusions: The MSCRQ appears to be a reliable and valid measure of metacognitions about self-critical rumination whilst the MCQ-30 is a better predictor of general emotional distress.

Key words: metacognition; negative affect; self-critical rumination; self-criticism; selfesteem. 


\section{Introduction}

\subsection{Rumination and psychopathology}

Rumination is the process of perseveratively thinking about one's emotions or problems without actively problem-solving or changing the circumstances for the better (Nolen-Hoeksema, Wisco, \& Lyubomirsky, 2008; Treynor, Gonzalez, \& Nolen-Hoeksema, 2003). The response styles theory proposed by Nolen-Hoeksema (1991) highlights the role that rumination plays in generating symptoms of depression, including low mood and social withdrawal, where several mechanisms are involved in activating, exacerbating and maintaining levels of distress. First, the act of ruminating enhances the effect of mood on cognitive processes, leading one to draw on negative thoughts and memories when contextualizing the present moment. In an attempt to improve mood, attention is then focused on trying to understand the emotional state and its potential causes, which then interrupts one's ability to effectively problem-solve; increasing social isolation and leading to further distress (Nolen-Hoeksema, 2004; Nolen-Hoeksema et al., 2008).

Research has also explored the role that the process of rumination has on other content-based thoughts aside from depression, such as anger (Baer \& Sauer, 2011; Bushman, Bonacci, Pedersen, Vasquez, \& Miller, 2005; Sukhodolsky, Golub, \& Cromwell, 2001), postevent processing (Abbott \& Rapee, 2004; Brozovich \& Heimberg, 2011, 2013) and worry (Rector, Antony, Laposa, Kocovski, \& Swinson, 2008). In each case, the content of the thought, when engaged in the process of rumination, can intensify the related emotion, such as anger and anxiety, and also have a negative impact on behavior.

\subsection{Self-criticism and self-critical rumination}

Recent research has started to explore the role that the process of rumination plays in maintaining levels of self-criticism (Kolubinski, Nikčević, Lawrence, \& Spada, 2015; Smart, Peters, \& Baer, 2015). Self-criticism is an intense and persistent form of internal dialogue 
that expresses hostility toward the self when one is unable to attain one's own high standards (Shahar, 2015). High levels of self-criticism have been associated with several mental health disorders, including depression (Blatt, 1995; Blatt, D’Afflitti, \& Quinlan, 1976), social anxiety (Cox et al., 2000; Cox, Fleet, \& Stein, 2004), PTSD (Cox, MacPherson, Enns, \& McWilliams, 2004; Littleton \& Henderson, 2009), psychosomatics (Rudich, Lerman, Gurevich, Weksler, \& Shahar, 2008) and eating disorders (Dunkley \& Grilo, 2007). However, high self-criticism is not necessarily specific to mental health disorders and can also decrease self-efficacy and impair long-term adjustment (Stoeber, Hutchfield, \& Wood, 2008; Zuroff, Koestner, \& Powers, 1994).

Previous studies have found that individuals displaying high levels of self-criticism are less likely to engage in problem-solving and are more likely to feel helpless or hopeless in stressful situations (Dunkley \& Blankstein, 2000; Flett, Hewitt, Blankstein, Solnik, \& Van Brunschot, 1996); characteristics also found in those who also engage in the process of rumination (Nolen-Hoeksema et al., 2008; Treynor et al., 2003). This has been highlighted in the findings that rumination appears to mediate the relationship between self-criticism and both depression and suicide ideation (O’Connor \& Noyce, 2008; Spasojević \& Alloy, 2001).

Smart et al. (2015) postulated that self-critical rumination may be a construct that is distinct from other forms of rumination, which is similar to what Verplanken et al. (2007) had earlier described as a mental habit of negative self-thinking. Depressive rumination, for example, contains elements of self-criticism; however, it primarily involves the process of perseveratively thinking about the causes and implications of one's symptoms of depression in an attempt to understand and change that emotional state (Nolen-Hoeksema \& Morrow, 1991; Nolen-Hoeksema et al., 2008; Treynor et al., 2003). Self-critical rumination, on the other hand, is the process of focusing attention specifically on self-critical thoughts, aspects 
of the self of which one is ashamed and one's overall self-worth, rather than on emotions. These thoughts can be considered transdiagnostic and are entirely self-focused.

Additionally, Trapnell and Campbell (1999) distinguish between the tendency to ruminate on past mistakes or disappointing moments from the ability to engage in reflection, where the latter refers to a process of introspection and self-analysis without negative judgement. The Rumination and Reflection Questionnaire (RRQ) was created in order to measure this distinction. Smart et al., (2015), however, demonstrated that their Self-Critical Rumination Scale (SCRS) predicted levels of distress over and above the RRQ-rumination scale. They also stated that although the two measures were highly correlated $(\mathrm{r}=.81, \mathrm{p}<$ $.001)$, the RRQ focuses on rumination that is self-focused, but is not entirely self-critical.

\subsection{Metacognition in self-critical rumination}

A theoretical framework that could be used to explain the process of self-critical rumination is the Self-Regulatory Executive Function (S-REF) model described by Wells and Matthews (1994, 1996). In this model, emphasis is placed not on the content of one's intrusive thoughts and experiences, but rather on the mechanisms that generate, monitor and maintain them (Wells, 2009). Psychological distress is linked to the activation of a particularly toxic style of thinking, consisting of worry and rumination, an over-developed sense of threat and unhelpful coping mechanisms, such as thought suppression and avoidance. This style of thinking, referred to as the Cognitive Attentional Syndrome (CAS), is based on metacognitions, which are the beliefs that we hold about our cognitive experience and how to control it.

To date, metacognitions have helped to understand the processes involved in problem drinking (Caselli \& Spada, 2013; Spada \& Wells, 2006), problem gambling (Spada, Giustina, Rolandi, Fernie, \& Caselli, 2014), nicotine use (Nikčević \& Spada, 2010), procrastination (Fernie \& Spada, 2008), anger (Simpson \& Papageorgiou, 2003) and depressive rumination 
(Papageorgiou \& Wells, 2001a, 2001b). The S-REF model is also central to Metacognitive Therapy (MCT), which has been successfully applied to the treatment of psychological disorders (Normann, Van Emmerik, \& Morina, 2014; Wells, 2009).

More recently, Kolubinski et al. (2015) interviewed individuals with low self-esteem, who did not qualify for a diagnosis of a mental health disorder, about their perceptions of, and experience with, their self-critical thoughts. In doing so, they identified several justifications for why individuals might engage in self-critical rumination. According to the S-REF model, these justifications are defined as positive metacognitions, which include: 'Because it will keep one from becoming lazy or complacent;' or 'Because it will keep one from making mistakes in the future'.

Equally, however, the participants in this study also acknowledged that dwelling on self-critical thoughts for too long could potentially be emotionally damaging and that they were unable to shift the focus of their attention away from their self-critical thoughts. This perspective represents an individual's negative metacognitions and demonstrates that whilst self-criticism may be a common experience for most people (Gilbert, Clarke, Hempel, Miles, \& Irons, 2004; Noordenbos, Aliakbari, \& Campbell, 2014), there may be an inherent contradiction between the justification of engaging in self-critical rumination on the one hand and an inability to control or detach from self-critical thoughts on the other. This contradiction, coupled with the perceived inability to control this process, acts to maintain the focus of attention on the unpleasant intrusive thoughts, leading to an increase in rumination and inability to shift attention away or engage in a more productive activity, such as problemsolving (Wells, 2009).

The content of these metacognitions were similar in nature to some of those found in the Positive Beliefs about Rumination Scale (PBRS) by Papageorgiou \& Wells (2001a) regarding depressive rumination. For example, in both instances, individuals indicated that 
ruminating on the past could help one to improve performance in the future, demonstrating similar justifications for ruminating. The difference, however, is the content of the rumination that follows. In the case of depressive rumination, the individual focuses attention on the symptoms of depression (Nolen-Hoeksema, 1991; Nolen-Hoeksema \& Morrow, 1991), whereas self-critical rumination involves focusing on one's lack of self-worth and self-critical thoughts, independent of a specific psychological disorder or emotional state (Smart et al., 2015).

\subsection{Aims of our study}

The aim of our two studies was to develop and validate a measurement of metacognitions involved in the process of self-critical rumination. Based on the Metacognitions Questionnaire (Cartwright-Hatton \& Wells, 1997; Wells \& Cartwright-Hatton, 2004) and the responses from the interviews garnered in Kolubinski et al.'s study (2015) we hypothesized that both positive and negative metacognitions would be correlated with established measures of self-esteem, self-criticism, self-critical rumination, negative affect and general metacognitions, and that they would predict self-critical rumination and levels of general distress independently of these established measures.

\section{Study 1: Construction of the Metacognitions about Self-Critical Rumination Questionnaire}

\section{Method}

\subsection{Participants}

A convenience sample of 178 participants $(138$ female; mean age $=39.51$ years $[\mathrm{SD}=11.83$; range 18 to 75 years]) was recruited for this study and completed the preliminary version of the Metacognitions about Self-Critical Rumination Questionnaire (MSCRQ). Participants were required: (1) to be at least 18 years of age; and (2) to consent to participate. Eligibility criteria were minimal to attract a sample that represented a broad range of individuals. 
However, despite this, the ethnic background of this sample was heavily skewed with $87.1 \%$ stating their ethnicity as Caucasian, followed by 5.1\% Asian, $2.8 \%$ Mixed Race, $1.7 \%$ each of Black, Other Background and Not Stated.

\subsection{Materials}

Fifteen items pertaining to metacognitions about self-critical rumination were derived from a review of transcriptions of an earlier qualitative study (Kolubinski et al., 2015), as well as from the authors' clinical experience and deductions based on theory, to form the raw version of the MSCRQ. Items were framed as statements to which participants could respond to on a four-point Likert-type scale to indicate their level of agreement ("1. Do not agree", "2. Agree slightly", “3. Agree moderately", and "4. Agree strongly"). The items were preceded by a pre-amble that read as follows:

"Experiencing judgmental thoughts about self-worth is very common. These typically relate to perceived mistakes and failures (e.g. "I didn't do as well as I should have") and an inability to live up to one's own or others' standards (e.g. “I'm not good enough").

Spending time thinking about these types of thoughts is also very common. This typically involves reviewing past actions, wondering how things could have turned out differently, and focusing attention on aspects of ourselves that we may be ashamed of. Listed below are beliefs that people have expressed regarding this style of thinking. Please read each item and select how much you generally agree with it."

\subsection{Procedure}

Participants were recruited via the Internet by posting a hyperlink to the study on various websites targeting individuals with low self-esteem and/or high in self-criticism. The study was also advertised at a London university where students were asked to volunteer their time for credit. An additional recruitment strategy involved emailing a hyperlink to the online 
questionnaires to individuals on the authors' email contact lists and asking recipients to forward this on to others on their contact lists, in attempt to create a viral-like spread.

Potential participants were directed to the study website containing the MSCRQ. The first page of this provided information regarding the purpose of the study, how responses were anonymised, and that consent would be assumed once participants click on the 'submit' button upon completion of the battery of questionnaires. The pages following this information contained a series of questions to ascertain participants' demographic details. Participants were not required to record their names.

\section{Results}

\subsection{Principal Components Analysis}

The fifteen original items of the MSCRQ were subjected to a principal components analysis (PCA) using SPSS (version 21; IBM Corp, 2012). Three factors were initially suggested. However, following a parallel analysis, the third factor with an eigenvalue of 1.01 was removed, resulting in a two-factor solution (Henson \& Roberts, 2006; Patil, Singh, Mishra, \& Donovan, 2008).

We then assessed the items as indicators of the latent variables using a Promax rotation adopting kappa $=4$. An oblique rotation was chosen in order to also assess the correlation between factors. It was decided a priori that items that loaded less than .4 on either factor would be discarded, as would be items that loaded above .4 on both factors. If, however, an item loaded more than .4 on only one factor, but the second factor loading was within .2 of the loading on the first factor, it would also be discarded. For example, if a factor loaded .5 on the first factor, it would be discarded if the loading on the second factor was above .3. This figure was used in order to exclude items that influenced both factors. None of the items met the exclusion criteria. This lead to a two-factor solution (eigenvalues of 5.57 and 1.89) of the scores for the selected 15 items, which accounted for $49.7 \%$ of the variance 
and the estimated correlation between the two factors was 0.43 (Table 1 shows the factor loadings of the individual items). Finally, we repeated the item selection procedure using a Varimax rotation and obtained the same final subset of items. We thus retained the original 15-item MSCRQ for the second study, where the measurement would be subjected to a confirmatory factor analysis using a new data set.

\section{Study 2: Validation of the MSCRQ}

\section{Introduction}

In order to validate the MSCRQ and provide support for assessing levels of metacognitions about self-critical rumination we: (1) determined construct validity (by running a Confirmatory Factor Analysis; CFA); (2) established concurrent validity (by observing whether the two factors of the MCSRQ would correlate significantly with established measures of self-esteem, self-criticism, self-critical rumination, negative affect and general metacognitions); (3) examined internal reliability; (4) examined incremental validity by observing whether the MSCRQ would predict levels of self-critical rumination when controlling for affect, self-criticism, self-esteem and general metacognitions about worry and also by observing whether the MSCRQ would predict levels of distress when controlling for self-criticism, self-esteem, and self-critical rumination and general metacognitions about worry.

\section{Method}

\subsection{Participants}

A sample of 247 participants ( 153 female; mean age $=44.78$ years $[\mathrm{SD}=12.35$; range 18 to 75 years]) completed a battery of online questionnaires. Eligibility matched that employed in

Study 1. Again, the ethnic background of participants was heavily skewed, with $89.9 \%$ reporting their ethnicity as Caucasian, followed by $4.5 \%$ Asian, $1.6 \%$ Mixed Race, $0.8 \%$ Black, $0.8 \%$ Other, and $2.4 \%$ Not Stated. 


\subsection{Materials}

\subsubsection{Self-esteem measure}

The Rosenberg Self-Esteem Questionnaire (RSES; Rosenberg, 1965) is a widely-used measurement of self-esteem. It is a 10-item measure using a 4-point Likert scale and scores range either between $0-30$ or 10-40, depending on whether the scale runs from 0 to 3 or 1 to 4. Self-esteem is considered to be 'low' if the total scores falls two standard deviations below the mean, which is approximately 14 or 24 , depending on how it is scored (Pack \& Condren, 2014; Schmitt \& Allik, 2005). The RSES has demonstrated good reliability and validity across many sample groups (Robinson, Wrightsman, \& Andrews, 1991).

\subsubsection{Self-criticism measure}

The Depressive Experiences Questionnaire Self-Criticism 6 (DEQ-SC6; Rudich, Lerman, Gurevich, Weksler, \& Shahar, 2008) is a 6-item measure derived from the Depressive Experiences Questionnaire (Blatt et al., 1976) and uses a 7-point Likert scale to assess levels of self-criticism. The DEQ-SC6 demonstrates acceptable levels of reliability and validity (Rudich et al., 2008).

\subsubsection{Self-critical rumination measure}

The Self-Critical Rumination Scale (SCRS; Smart, Peters, \& Baer, 2015) assesses the ruminative process associated with self-critical thoughts. This is a 10-item measure that uses a 4-point Likert scale, has excellent internal consistency and correlates highly with measures of self-criticism as well as measures of rumination (Smart et al., 2015). It should be noted, however, that whilst the scale contains items such as 'I often worry about all of the mistakes I have made' and 'My attention is often focused on aspects of myself that I'm ashamed of' which are a reflection of the process of self-critical rumination, it also contains three items that assesses a belief about the lack of control over one's thoughts, which is the definition of a negative metacognition (e.g., 'Sometimes it is hard for me to shut off critical thoughts about 
myself'). For the purposes of this study, we removed the three metacognitive items $(\# 3,4,7)$ in order to better distinguish between self-critical rumination and the metacognitions related to it. The resulting 7 questions still maintained excellent reliability $(\alpha=.911)$ and correlated very strongly with the original 10 -item version $(r=.99, \mathrm{p}<.001)$.

\subsubsection{Metacognitions measure}

The Metacognitions Questionnaire 30 (MCQ-30; Wells \& Cartwright-Hatton, 2004) is a 30item measure that assesses metacognitions in psychopathology using a 4-point Likert scale. Five factors are assessed, which include: (a) positive beliefs about worry (POS); (b) negative beliefs about thoughts concerning danger and uncontrollability (NEG); (c) levels of cognitive confidence (CC); (d) beliefs about the need to control thoughts (NC); and (e) cognitive selfconsciousness (CSC). For the purposes of this study, we opted to use the MCQ-30 as opposed to other measures of metacognition in order to compare the two-factor MSCRQ to the five factors that it measures. The MCQ-30 has demonstrated good internal consistency and convergent validity and has acceptable test-retest reliability (Spada, Mohiyeddini, \& Wells, 2008; Wells \& Cartwright-Hatton, 2004).

\subsubsection{Negative affect measure}

The short form of the Depression Anxiety Stress Scales (DASS-21; Antony, Bieling, Cox, Enns, \& Swinson, 1998) is a 21-item measure using a 4-point Likert scale that assesses general symptoms of psychopathology. The DASS-21 distinguishes between depression, physiological arousal and psychological agitation. It has acceptable reliability and has been validated using clinical and non-clinical populations. It contains three orthogonal factors (depression (DASS-D), anxiety (DASS-A) and stress (DASS-S) as well as an overall factor of psychological distress (DASS-T) (Henry \& Crawford, 2005).

\subsection{Procedure}

This followed the same structure as in Study 1. 


\section{Results}

\subsection{Confirmatory Factor Analysis}

A CFA was performed on the data obtained from the participants using lavaan in $\mathrm{R}$ (Version 0.5-22; Rosseel, 2012). We defined the latent variables as positive and negative metacognitions about self-critical rumination and the 15 items as congeneric indicators of the latent variables. Using a robust weighted least squares estimation (WLSMV), we did not assume multivariate normality of item scores and defined them as ordinal indicators within the model. We utilized four indices to evaluate the fit of the model: a Chi-square measure of fit, the Comparative Fit Index (CFI), the Tucker-Lewis Index (TLI: also known as the Non-Normed Fit Index) and the Root Mean Square Error of Approximation (RMSEA).

Two models were first compared to ensure best fit (See Table 2). The initial CFA assumed orthogonality between the latent variables and resulted in a weak fit: the chi-square test was significant $\left(\chi^{2}=416.10, \mathrm{df}=90, \mathrm{p}>.001\right)$ and the $\chi^{2} / \mathrm{df}=4.62$. This model generated a CFI of 0.75 , a TLI of 0.71 and an RMSEA of $0.121(\mathrm{p}<.001)$. Model 2 accounted for covariances among the latent variables: the chi-square test remained significant $\left(\chi^{2}=\right.$ 240.79, $\mathrm{df}=89, \mathrm{p}>.001), \chi^{2} / \mathrm{df}=2.71$. The CFA generated a CFI of 0.88 and TLI of 0.86 , and the RMSEA was 0.083 ( $\mathrm{p}>0.05$ ), also suggesting weak fit.

Parameter estimates were reviewed and modification indices were calculated. Together these suggested that a re-specified model, resulting from the removal of 5 items $(\# 3,9,10,12$, 14). The re-specified model retained the covariances between latent variables and acceptable fit of the data was demonstrated (See Figure 1). Although the Chi-square test remained significant $\left(\chi^{2}=56.25\right.$, df $\left.=34 \mathrm{p}<.05\right)$, the resulting $\chi^{2} / \mathrm{df}=1.65$ suggests acceptable fit (Byrne, 2001). This new model also yielded the following results: CFI of 0.97, TLI of 0.96 and RMSEA of 0.052 ( $\mathrm{p}>0.05)$, demonstrating acceptable construct validity (See Table 2). In order to verify the correlated two-factor model, Model 4 included all 10 items in a single 
factor. In this model the results were: $\chi^{2}=139.27(\mathrm{df}=35, \mathrm{p}>.001)$, and $\chi^{2} / \mathrm{df}=3.98$, generating a CFI of 0.86 , TLI of 0.82 and RMSEA of $0.110(\mathrm{p}<0.001)$. Based on these four models, Model 3 was the best fit for the data and the MSCRQ was confirmed as having two correlated factors, negative metacognitions about self-critical rumination (MSCRQ-N; 6 items) and positive metacognitions about self-critical rumination (MSCRQ-P; 4 items).

\subsection{MSCRQ sub-scales and reliability}

Reliability was calculated using Zumbo's Ordinal Alpha by using a polychoric correlation coefficient (Gadermann, Guhn, \& Zumbo, 2012; Zumbo, Gadermann, \& Zeisser, 2007). This appears to be a more valid test of reliability for ordinal data, such as Likert scales, than Cronbach's alpha which assumes continuous variables (Cronbach, 1951). The MSCRQ-N consisted of 6 items $(\alpha=.88)$, demonstrating good levels of reliability. The MSCRQ-P demonstrated acceptable levels of reliability (4 items; $\alpha=.74$ ).

\subsection{Concurrent validity}

Table 3 shows the means, standard deviations, and ranges for all the study variables. A series of Kolmogorov-Smirnov tests of normality were conducted on the data, which suggested that all measurements were significantly different than normal. As a result a series of nonparametric, Spearman's Rho correlation analyses were conducted on the data (see Table 4). These revealed that the MSCRQ-P and MSCRQ-N were moderately correlated with each other and were significantly correlated with each of the other measures, with the exception of the MSCRQ-P and the MCQ-30 (CC).

The resulting MSCRQ-N strongly correlated with the Modified SCRS and DEQ-SC6, two subscales of the MCQ-30 (NEG and NC) and all four factors of the DASS. There was also a strong negative correlation with the RSES. The MSCRQ-N was moderately correlated with two other subscales of the MCQ-30 (CC and CSC) and weakly correlated with the MCQ-30 
(POS). This pattern is very similar to the correlations between the MCQ-30 (NEG) and subsequent measures.

The MSCRQ-P was strongly correlated with the MCQ-30 (POS). It was also moderately correlated with the Modified SCRS, the DEQ-SC6, three of the other subscales of the MCQ-30 (NEG, NC \& CSC), two of the DASS subscales (DASS-A, DASS-S) and the overall DASS-T. The MSCRQ-P was weakly correlated with the DASS-D. There was also a moderate negative correlation with the RSES. Again, this pattern is similar to the correlations between the MCQ-30 (POS) and the other measurements, although the MSCRQ-N correlated stronger with the measurements of self-criticism, self-critical rumination and self-esteem. Notably, neither the MSCRQ-P nor the MCQ-30 POS were significantly correlated with the MCQ-30 (CC) subscale.

\subsection{Incremental validity}

Incremental validity was ascertained by performing a regression analysis in which the modified version of the SCRS was the dependent variable and the predictor variables were entered in the following order: negative affect, self-criticism, self-esteem, positive metacognitions about self-critical rumination, negative metacognitions about self-critical rumination and general metacognitions about worry. This order was chosen to test whether metacognitions about self-critical rumination could predict self-critical rumination when controlling for the first three factors and then see if an established measure of metacognitions could serve as a stronger predictor of self-critical rumination. Following the first four steps, the DASS, DEQ-SC6 and RSES accounted for a significant amount of the variance $\left(\mathrm{R}^{2}=.75\right.$, $p<.001)$. The addition of the MSCRQ-P resulted in a significant change $\left(\mathrm{R}^{2}=.77, \mathrm{p}<.01\right)$ as did the addition of the MSCRQ-N $\left(\mathrm{R}^{2}=.81, \mathrm{p}<.001\right)$. The MCQ-30 did not result in a significant increase in the variance $\left(\mathrm{R}^{2}\right.$ change $=.005$, n.s. $)$. After the addition of the MCQ30, however, the MSCRQ-P became a non-significant predictor. Thus, the MSCRQ-N 
subscale was a predictor of levels of self-critical rumination after controlling for the other factors $(\mathrm{B}=.47, \mathrm{p}<.001[\mathrm{LL}=0.32, \mathrm{UL}=0.62])$, but the MSCRQ-P was not. In this model, depression, anxiety, stress and negative metacognitions about worry were non-significant predictors of self-critical rumination (See Table 5).

\subsection{Impact of the metacognitions about self-critical rumination on distress}

To measure the impact of metacognitions about self-critical rumination on overall distress, a second regression analysis was conducted in which the criterion variable was the overall distress scale of the DASS. This is an indicator of general symptoms of psychopathology that correlates highly with levels of depression, anxiety and physiological stress (Henry \& Crawford, 2005). We believe that this serves as a suitable proxy for each of the subscales, rather than conducting three separate analyses. Predictor variables were entered in the following order: self-criticism, self-esteem, self-critical rumination, positive metacognitions about self-critical rumination, negative metacognitions about self-critical rumination and general metacognitions about worry. Again, this order was chosen to test whether metacognitions about self-critical rumination could predict distress when controlling for the first three factors and then see if an established measure of metacognitions would serve as a stronger predictor. Following the first three steps, the DEQ-SC6, RSES and SCRS-M accounted for a significant amount of the variance $\left(\mathrm{R}^{2}=.56, \mathrm{p}<.001\right)$. The addition of the MSCRQ-P did not result in a significant change, but the MSCRQ-N did $\left(\mathrm{R}^{2}=.58, \mathrm{p}<.05\right)$. Thus, the MSCRQ-N subscale was a predictor of levels of distress after controlling for the other factors $(\mathrm{B}=.68, \mathrm{p}<.05[\mathrm{LL}=0.143, \mathrm{UL}=1.22]$, as was the modified version of the SCRS $(\mathrm{B}=.61, \mathrm{p}<.05[\mathrm{LL}=0.09, \mathrm{UL}=1.12]$. However, following the inclusion of the MCQ-30 subscales, the MSCRQ-N was no longer a significant predictor of distress, nor was the modified version of the SCRS. In this model, self-esteem and two of the MCQ-30 subscales were the only significant predictors of distress (NEG and NC), suggesting that the 
MCQ-30, rather than the MSCRQ, may account for the relationship between self-critical rumination and distress (See Table 6).

\section{Discussion}

The central aim of this study was to develop a brief measure of the metacognitions about selfcritical rumination. The end result of our analyses yielded a 10 -item measure that assesses the presence of positive ( 4 items) and negative (6 items) metacognitions that may play a key role in activating and maintaining the ruminative process linked to self-criticism. The final version of the MSCRQ demonstrated a good fit for the data.

The subscales of the MSCRQ also demonstrated appropriate concurrent validity, where both the MSCRQ-N and MSCRQ-P correlated strongly with their respective subscales on the MCQ-30, a well-established measurement of metacognitions about worry (Spada et al., 2008; Wells \& Cartwright-Hatton, 2004). There was also a strong correlation between the MSCRQ-N and the SCRS, which measures levels of self-critical rumination. This high correlation, however, would be expected if an inability to detach from these thoughts, and concern that these thoughts will cause harm or distress, are key elements in the maintenance of the ruminative process, as expounded in the S-REF model.

It is important to note that Smart et al. (2015) did not distinguish between the ruminative process and the corresponding metacognitions that activate and maintain selfcritical rumination, as evidenced by three metacognitive items in the SCRS. The initial 10item measurement, however, had excellent inter-item reliability, which suggests a strong relationship between the ruminative process and associated metacognitions with respect to self-criticism. By removing the three items, the correlation between the two scales decreased to 0.82 , which is still very high and questions the potential lack of divergent validity.

The MSCRQ-N subscale predicted levels of self-critical rumination when controlling for other relevant factors, demonstrating incremental validity. The MSCRQ-P demonstrated 
statistical significance when predicting self-critical rumination prior to the inclusion of the MCQ-30, which itself did not account for a significant increase in the variance. The presence of redundant predictor variables may have impacted the ability for the MSCRQ-P to reach statistically significant levels of prediction. With respect to levels of distress, though, the MSCRQ-N was only able to predict levels of general distress when accounting for levels of self-criticism, self-esteem and self-critical rumination. The MCQ-30, on the other hand, appears to account for the association between self-critical rumination and general distress above the MSCRQ. This may be because the high correlation between the SCRS and MSCRQ means that neither measure will account for much variance in distress scores above the other, where the MCQ-30 might.

The results of this study provide further evidence that self-critical rumination accounts for the relationship between self-criticism and distress and also adds that metacognitions measured by the MSCRQ and MCQ-30 may further account for the relationship between self-critical rumination and distress (James, Verplanken, \& Rimes, 2015; Smart et al., 2015; Spada et al., 2008; Spasojević \& Alloy, 2001). Self-criticism as a construct is transdiagnostic and not solely linked to mood disorders (Blatt, 1995; Cox et al., 2000; Cox, Fleet, et al., 2004; Littleton \& Henderson, 2009; Rudich et al., 2008) and the associated ruminative process should reflect that. Research into self-critical rumination is still in its infancy, though, and further research will be required to distinguish it from other styles of rumination. The positive metacognitions that we have cited above, for example, are similar to the ones associated with depressive rumination (Papageorgiou \& Wells, 2001b). Since the positive metacognitions appear to account for less of the variance of self-critical rumination, though, it is possible that positive metacognitions are less important in maintaining levels of self-critical rumination. Indeed, it may be possible that the justifications for engaging with self-critical thoughts are generally shared across much of the population 
and instead it is the presence of negative metacognitions that maintains self-critical rumination.

The negative metacognitions measured by the MCQ-30 and the subscale that measures that need for control appears to predict greater levels of distress than the MSCRQ and SCRS. This suggests that the metacognitions about worry also play a significant role in distress over and above self-critical rumination and its associated metacognitions. Future research could focus on better understanding the relationship between worry, self-critical rumination and their respective contribution to distress. It might be the case that ruminating on past mistakes increases the likelihood that one will predict negative consequences for the future and it is the worry, rather than the rumination, that leads to greater levels of distress. It would also be important to understand the impact that self-critical rumination has on acute levels of stress rather than general levels of depression, anxiety or stress.

\subsection{Potential role of Metacognitive Therapy as an alternative to CBT}

Over the last 15 years there has been an increase in research on the effectiveness of cognitivebehavioural interventions aimed at raising levels of self-esteem showing that this form of treatment is of value (Brown et al., 2008; Fennell, 1997, 1999; Horrell et al., 2014; Pack \& Condren, 2014; Waite, McManus, \& Shafran, 2012). Whilst self-esteem remained a significant factor in predicting distress, this study also demonstrates the importance of attending to metacognitions about worry and self-critical rumination independent of the level of self-esteem. In traditional cognitive-behavioural interventions for low self-esteem, metacognitions and self-critical rumination are not directly addressed. Previous research has demonstrated that there is a relationship between attempts to suppress negative self-referent thoughts and lower self-esteem (Borton \& Casey, 2006; Borton, Markowitz, \& Dieterich, 2005). It follows that there may be a potential role for Metacognitive Therapy (MCT; Wells, 2009) in tackling worry and self-critical rumination in the treatment for low self-esteem. 
Rather than judging oneself positively or negatively, and addressing the validity of the content of one's thoughts, from the MCT perspective it might be more clinically beneficial to teach clients about the nature of intrusive thoughts and appropriate ways to respond to them.

MCT is an effective form of treatment for psychological disorders (Normann et al., 2014). With respect to how we interact with our intrusive thoughts, Wells (2009) makes a distinction between 'object' mode, where thoughts are not distinguished from sensory experiences and both inner and outer events are treated equally, and 'metacognitive' mode, where thoughts can be observed as being separate from the self and external world and their veracity is not automatically assumed. In treatment, individuals are taught techniques such as detached mindfulness, which help them to see thoughts as passing events in the mind and they are taught how to shift their focus of attention away from the perseverate processes. Whilst the presence of occasional self-critical thoughts is normative (Shahar, 2015; Whelton \& Greenberg, 2005), individuals with low self-esteem and high levels of self-critical rumination could learn to respond to these thoughts without ruminating on them.

From this perspective, individuals could learn about the relenting nature of one's own internal critic and worrier and taught to observe and 'detach' from them rather than challenging their validity. Other forms of therapy, such as Rational-Emotive Behavior Therapy (Ellis, 2005), Acceptance and Commitment Therapy (Harris, 2010) and Compassion-Focused Therapy (Gilbert, 2009) use similar techniques to develop selfacceptance and self-compassion rather than attempting to raise self-esteem.

\subsection{Limitations}

There are several limitations that should be considered in the interpretation of these conclusions. First, data was solely based on self-report questionnaires, which may be subject to social desirability, self-report errors and poor recall. Future research could use more objective measures in order to ascertain the individual experience of positive and negative 
metacognitions. Second, this study used a cross sectional design, which does not allow for causal inferences. It remains unknown at present whether positive and negative metacognitions about worry or self-critical rumination engender either higher levels of selfcriticism or more time ruminating on this content. Third, the participants in this study are not representative of the general population. There was a disproportionately higher level of female participants and the sample was overwhelmingly Caucasian. A larger sample size might have been able to correct for this. Furthermore, country of origin was not ascertained in this study and participants could have completed the questionnaires online anywhere in the world so long as they were able to speak and read English. Future research is required in order to ascertain cultural and linguistic generalizability.

In order to differentiate between the ruminative process and the metacognitions that activate and maintain that process, we treated them as separate constructs. However, if the beliefs that self-critical rumination is harmful and outside of one's control are the sole driver of that rumination, then it may be more efficient to treat them as a single construct. This would account for the high inter-item reliability of the original SCRS, which included metacognitive items, and the strong relationship between the 10-item SCRS and MSCRQ-N. Similarly, in view of the possible overlap between metacognitions about self-critical rumination and depressive rumination, future research should examine whether these are indeed separate constructs. The role that self-criticism appears to have on other disorders aside from depression, however, suggests that they might (Cox et al., 2000; Cox, Fleet, et al., 2004; Cox, MacPherson, et al., 2004; Dunkley \& Grilo, 2007; Rudich et al., 2008).

\subsection{Conclusions}

Despite these limitations, we believe that the MSCRQ is tool that could prove useful in better understanding the metacognitive processes that activate and maintain self-critical rumination. It appears to demonstrate acceptable levels of reliability and validity in ascertaining beliefs 
about the usefulness of ruminating on self-critical thoughts as well the reported inability to detach from them once they start. Shahar (2015) makes a distinction between pathological self-criticism and the normative, transient moments of 'self-bashing'. The process of selfcritical rumination, separate from other forms of rumination, could explain the distinction between the two. 


\section{References}

Abbott, M. J., \& Rapee, R. M. (2004). Post-event rumination and negative self-appraisal in social phobia before and after treatment. Journal of Abnormal Psychology, 113(1), 136144. https://doi.org/10.1037/0021-843X.113.1.136

Antony, M. M., Bieling, P. J., Cox, B. J., Enns, M. W., \& Swinson, R. P. (1998).

Psychometric properties of the 42-item and 21-item versions of the Depression Anxiety Stress Scales in clinical groups and a community sample. Psychological Assessment, 10(2), 176-181. https://doi.org/10.1037/1040-3590.10.2.176

Baer, R. A., \& Sauer, S. E. (2011). Relationships between depressive rumination, anger rumination, and borderline personality features. Personality Disorders, 2(2), 142-50. https://doi.org/10.1037/a0019478

Blatt, S. J. (1995). The destructiveness of perfectionism: Implications for the treatment of depression. American Psychologist, 50(12), 1003-1020. https://doi.org/10.1037/0003066X.50.12.1003

Blatt, S. J., D’Afflitti, J. P., \& Quinlan, D. M. (1976). Experiences of depression in normal young adults. Journal of Abnormal Psychology, 85(4), 383-389.

Borton, J. L. S., \& Casey, E. C. (2006). Suppression of negative self-referent thoughts: A field study. Self and Identity, 5(3), 230-246.

https://doi.org/10.1080/15298860600654749

Borton, J. L. S., Markowitz, L. J., \& Dieterich, J. (2005). Effects of suppressing negative self-referent thoughts on mood and self-esteem. Journal of Social and Clinical Psychology, 24(2), 172-190. https://doi.org/10.1521/jscp.24.2.172.62269

Brown, J. S. L., Elliott, S. A., Boardman, J., Andiappan, M., Landau, S., \& Howay, E. (2008). Can the effects of a 1-day CBT psychoeducational workshop on self-confidence be maintained after 2 years? A naturalistic study. Depression and Anxiety, 25(7), 632- 
640. https://doi.org/10.1002/da.20365

Brozovich, F. A., \& Heimberg, R. G. (2011). The relationship of post-event processing to self-evaluation of performance in social anxiety. Behavior Therapy, 42(2), 224-235. https://doi.org/10.1016/j.beth.2010.08.005

Brozovich, F. A., \& Heimberg, R. G. (2013). Mental imagery and post-event processing in anticipation of a speech performance among socially anxious individuals. Behavior Therapy, 44(4), 701-716. https://doi.org/10.1016/j.beth.2013.07.001

Bushman, B. J., Bonacci, A. M., Pedersen, W. C., Vasquez, E. A., \& Miller, N. (2005). Chewing on it can chew you up: Effects of rumination on triggered displaced aggression. Journal of Personality and Social Psychology, 88(6), 969-983. https://doi.org/10.1037/0022-3514.88.6.969

Byrne, B. M. (2001). Structural Equation Modeling with AMOS, basic concepts, applications, and programming. Hillsdale, NJ: Lawrence Erlbaum Associates, Inc.

Cartwright-Hatton, S., \& Wells, A. (1997). Beliefs about worry and intrusions: The MetaCognitions Questionnaire and its correlates. Journal of Anxiety Disorders, 11(3), 279296. https://doi.org/10.1016/S0887-6185(97)00011-X

Caselli, G., \& Spada, M. M. (2013). The metacognitions about desire thinking questionnaire: Development and psychometric properties. Journal of Clinical Psychology, 69(12), 1284-1298. https://doi.org/10.1002/jclp.21999

Cox, B. J., Fleet, C., \& Stein, M. B. (2004). Self-criticism and social phobia in the US national comorbidity survey. Journal of Affective Disorders, 82(2), 227-234. https://doi.org/10.1016/j.jad.2003.12.012

Cox, B. J., MacPherson, P. S. R., Enns, M. W., \& McWilliams, L. A. (2004). Neuroticism and self-criticism associated with posttraumatic stress disorder in a nationally representative sample. Behaviour Research and Therapy, 42(1), 105-114. 
Cox, B. J., Rector, N. A., Bagby, R. M., Swinson, R. P., Levitt, A. J., \& Joffe, R. T. (2000). Is self-criticism unique for depression? A comparison with social phobia. Journal Of Affective Disorders, 57(1-3), 223-228. https://doi.org/10.1016/S0165-0327(99)00043-9

Cronbach, L. J. (1951). Coefficient alpha and the internal structure of tests. Psychometrika, 16(3), 297-334.

Dunkley, D. M., \& Blankstein, K. R. (2000). Self-critical perfectionism, coping, hassles, and current distress: A structural equation modeling approach. Cognitive Therapy and Research, 24(6), 713-730. https://doi.org/10.1023/A:1005543529245

Dunkley, D. M., \& Grilo, C. M. (2007). Self-criticism, low self-esteem, depressive symptoms, and over-evaluation of shape and weight in binge eating disorder patients. Behaviour Research and Therapy, 45(1), 139-149. https://doi.org/10.1016/j.brat.2006.01.017

Ellis, A. (2005). The myth of self-esteem: How rational-emotive behavior therapy can change your life forever. Amherst, NY: Prometheus Books.

Fennell, M. J. V. (1997). Low self-esteem: A cognitive perspective. Behavioural and Cognitive Psychotherapy, 25, 1-25.

Fennell, M. J. V. (1999). Overcoming low self-esteem. London: Robinsons.

Fernie, B. A., \& Spada, M. M. (2008). Metacognitions about procrastination: A preliminary investigation. Behavioural and Cognitive Psychotherapy, 36(3), 359-364.

Flett, G. L., Hewitt, P. L., Blankstein, K. R., Solnik, M., \& Van Brunschot, M. (1996). Perfectionism, social problem-solving ability, and psychological distress. Journal of Rational-Emotive \& Cognitive-Behavior Therapy, 14(4), 245-274. https://doi.org/10.1007/BF02238139

Gadermann, A. M., Guhn, M., \& Zumbo, B. D. (2012). Estimating ordinal reliability for Likert-Type and ordinal item response data: A conceptual, empirical, and practical 
guide. Practical Assessment, Research \& Evaluation, 17(3), 1-13. https://doi.org/http://pareonline.net/getvn.asp?v=17\&n=3

Gilbert, P. (2009). The compassionate mind. London: Constable \& Robinson Ltd.

Gilbert, P., Clarke, M., Hempel, S., Miles, J. N. V, \& Irons, C. (2004). Criticizing and reassuring oneself: An exploration of forms, styles and reasons in female students. The British Journal of Clinical Psychology, 43(1), 31-50.

Harris, R. (2010). The confidence gap: From fear to freedom. London: Constable \& Robinson Ltd.

Henry, J. D., \& Crawford, J. R. (2005). The short-form version of the Depression Anxiety Stress Scales (DASS-21): Construct validity and normative data in a large non-clinical sample. The British Journal of Clinical Psychology, 44(2), 227-239. https://doi.org/10.1348/014466505X29657

Henson, R. K., \& Roberts, J. K. (2006). Use of exploratory factor analysis in published research common errors and some comment on improved practiced. Educational and Psychological Measurement, 66(3), 393-416.

Horrell, L., Goldsmith, K. A., Tylee, A. T., Schmidt, U. H., Murphy, C. L., Bonin, E.-M., ... Brown, J. S. L. (2014). One-day cognitive-behavioural therapy self-confidence workshops for people with depression: Randomised controlled trial. The British Journal of Psychiatry, 204(3), 222-233.

IBM Corp. (2012). IBM SPSS Statistics for Windows, Version 21. Armonk, NY: IBM Corp. James, K., Verplanken, B., \& Rimes, K. A. (2015). Self-criticism as a mediator in the relationship between unhealthy perfectionism and distress. Personality and Individual Differences, 79, 123-128. https://doi.org/10.1016/j.paid.2015.01.030

Kolubinski, D. C., Nikčević, A. V., Lawrence, J. A., \& Spada, M. M. (2015). The role of metacognition in self-critical rumination: An investigation in individuals presenting with 
low self-esteem. Journal of Rational-Emotive and Cognitive-Behavior Therapy, 1-13. https://doi.org/10.1007/s10942-015-0230-y

Kupeli, N., Chilcot, J., Schmidt, U. H., Campbell, I. C., \& Troop, N. A. (2013). A confirmatory factor analysis and validation of the Forms of Self-criticism/Selfreassurance Scale. British Journal of Clinical Psychology, 52(1), 12-25.

Littleton, H., \& Henderson, C. E. (2009). If she is not a victim, does that mean she was not traumatized? Violence Against Women, 15(2), 148-167. https://doi.org/10.1177/1077801208329386

Nikčević, A. V., \& Spada, M. M. (2010). Metacognitions about smoking: A preliminary investigation. Clinical Psychology \& Psychotherapy, 17(6), 536-542.

Nolen-Hoeksema, S. (1991). Responses to depression and their effects on the duration of depressive episodes. Journal of Abnormal Psychology, 100(4), 569-582. https://doi.org/10.1037/0021-843X.100.4.569

Nolen-Hoeksema, S. (2004). The response styles theory. In C. Papageorgiou \& A. Wells (Eds.), Depressive rumination: Nature, theory and treatment (pp. 107-123). John Wiley \& Sons Inc.

Nolen-Hoeksema, S., \& Morrow, J. (1991). A prospective study of depression and posttraumatic stress symptoms after a natural disaster: The 1989 Loma Prieta earthquake. Journal of Personality and Social Psychology, 61, 115-121. https://doi.org/10.1037//0022-3514.61.1.115

Nolen-Hoeksema, S., Wisco, B. E., \& Lyubomirsky, S. (2008). Rethinking rumination. Perspectives on Psychological Science, 3(5), 400-424.

Noordenbos, G., Aliakbari, N., \& Campbell, R. (2014). The relationship among critical inner voices, low self-esteem, and self-criticism in eating disorders. Eating Disorders, 22(4), $337-51$. 
Normann, N., Van Emmerik, A. A. P., \& Morina, N. (2014). The efficacy of metacognitive therapy for anxiety and depression: A meta-analytic review. Depression and Anxiety, 31(5), 402-411. https://doi.org/10.1002/da.22273

O’Connor, R. C., \& Noyce, R. (2008). Personality and cognitive processes: Self-criticism and different types of rumination as predictors of suicidal ideation. Behaviour Research and Therapy, 46(3), 392-401. https://doi.org/10.1016/j.brat.2008.01.007

Pack, S., \& Condren, E. (2014). An evaluation of group cognitive behaviour therapy for low self-esteem in primary care. The Cognitive Behaviour Therapist, 7(e7), 1-10.

Papageorgiou, C., \& Wells, A. (2001a). Metacognitive beliefs about rumination in recurrent major depression. Cognitive and Behavioral Practice, 8(2), 160-164.

Papageorgiou, C., \& Wells, A. (2001b). Positive beliefs about depressive rumination: Development and preliminary validation of a self-report scale. Behavior Therapy, 32(1), 13-26. https://doi.org/10.1016/S0005-7894(01)80041-1

Patil, V. H., Singh, S. N., Mishra, S., \& Donovan, T. (2008). Efficient theory development and factor retention criteria: A case for abandoning the "Eigenvalue Greater Than One" criterion. Journal of Business Research, 61(2), 162-170.

Rector, N. A., Antony, M. M., Laposa, J. M., Kocovski, N. L., \& Swinson, R. P. (2008). Assessing content domains of repetitive thought in the anxiety spectrum: Rumination and worry in nonclinical and clinically anxious samples. International Journal of Cognitive Therapy, 1(4), 352-377.

Robinson, J. P., Wrightsman, L. S., \& Andrews, F. M. (Eds.). (1991). Measures of personality and social psychological attitudes. London: Elsevier.

Rosenberg, M. (1965). Society and the adolescent self-image. Princeton, NJ: Princeton University Press.

Rosseel, Y. (2012). lavaan: An R package for structural equation modeling. Journal of 
Statistical Software, 48(2), 1-36. Retrieved from http://www.jstatsoft.org/v48/i02/

Rudich, Z., Lerman, S. F., Gurevich, B., Weksler, N., \& Shahar, G. (2008). Patients'selfcriticism is a stronger predictor of physician's evaluation of prognosis than pain diagnosis or severity in chronic pain patients. Journal of Pain, 9(3), 210-216. https://doi.org/10.1016/j.jpain.2007.10.013

Schmitt, D. P., \& Allik, J. (2005). Simultaneous administration of the Rosenberg Self-Esteem Scale in 53 nations: Exploring the universal and culture-specific features of global selfesteem. Journal of Personality and Social Psychology, 89(4), 623-642. https://doi.org/10.1037/0022-3514.89.4.623

Shahar, G. (2015). Erosion: The psychopathology of self-criticism. New York, NY: Oxford University Press.

Simpson, C., \& Papageorgiou, C. (2003). Metacognitive beliefs about rumination in anger. Cognitive and Behavioral Practice, 10(1), 91-94.

Smart, L. M., Peters, J. R., \& Baer, R. A. (2015). Development and validation of a measure of self-critical rumination. Assessment, 23(3), 1-12.

Spada, M. M., Giustina, L., Rolandi, S., Fernie, B. A., \& Caselli, G. (2014). Profiling metacognition in gambling disorder. Behavioural and Cognitive Psychotherapy, 43(5), $614-622$.

Spada, M. M., Mohiyeddini, C., \& Wells, A. (2008). Measuring metacognitions associated with emotional distress: Factor structure and predictive validity of the Metacognitions Questionnaire 30. Personality and Individual Differences, 45, 238-242.

Spada, M. M., \& Wells, A. (2006). Metacognitions about alcohol use in problem drinkers. Clinical Psychology \& Psychotherapy, 13, 138-143.

Spasojević, J., \& Alloy, L. B. (2001). Rumination as a common mechanism relating depressive risk factors to depression. Emotion, 1(1), 25-37. 
Stoeber, J., Hutchfield, J., \& Wood, K. V. (2008). Perfectionism, self-efficacy, and aspiration level: Differential effects of perfectionistic striving and self-criticism after success and failure. Personality and Individual Differences, 45(4), 323-327. https://doi.org/10.1016/j.paid.2008.04.021

Sukhodolsky, D. G., Golub, A., \& Cromwell, E. N. (2001). Development and validation of the anger rumination scale. Personality and Individual Differences, 31(5), 689-700.

Trapnell, P. D., \& Campbell, J. D. (1999). Private self-consciousness and the five-factor model of personality: Distinguishing rumination from reflection. Journal of Personality and Social Psychology. https://doi.org/10.1037/0022-3514.76.2.284

Treynor, W., Gonzalez, R., \& Nolen-Hoeksema, S. (2003). Rumination reconsidered: A psychometric analysis. Cognitive Therapy and Research, 27(3), 247-259.

Verplanken, B., Friborg, O., Wang, C. E., Trafimow, D., \& Woolf, K. (2007). Mental habits: Metacognitive reflection on negative self-thinking. Journal of Personality and Social Psychology, 92(3), 526-541. https://doi.org/10.1037/0022-3514.92.3.526

Waite, P., McManus, F., \& Shafran, R. (2012). Cognitive behaviour therapy for low selfesteem: A preliminary randomized controlled trial in a primary care setting. Journal of Behavior Therapy and Experimental Psychiatry, 43(4), 1049-1057. https://doi.org/10.1016/j.jbtep.2012.04.006

Wells, A. (2009). Metacognitive therapy for anxiety and depression. New York, NY: Guilford Press.

Wells, A., \& Cartwright-Hatton, S. (2004). A short form of the metacognitions questionnaire: Properties of the MCQ-30. Behaviour Research and Therapy, 42(4), 385-396. https://doi.org/10.1016/S0005-7967(03)00147-5

Wells, A., \& Matthews, G. (1994). Attention and emotion: A clinical perspective. Hove, UK: Erlbaum. 
Wells, A., \& Matthews, G. (1996). Modelling cognition in emotional disorder: The S-REF model. Behaviour Research and Therapy, 34(11-12), 881-888.

Whelton, W. J., \& Greenberg, L. S. (2005). Emotion in self-criticism. Personality and Individual Differences, 38(7), 1583-1595.

Zumbo, B. D., Gadermann, A. M., \& Zeisser, C. (2007). Ordinal versions of coefficients alpha and theta for likert rating scales. Journal of Modern Applied Statistical Methods, 6(1), 21-29. https://doi.org/10.1107/S0907444909031205

Zuroff, D. C., Koestner, R., \& Powers, T. A. (1994). Self-criticism at age 12: A longitudinal study of adjustment. Cognitive Therapy and Research, 18(4), 367-385. https://doi.org/10.1007/BF02357511 
Table 1: Factor loadings from exploratory factor analysis.

1. I find it hard to focus on anything else when I think about my past

.79

$-.02$ mistakes and failures

2. I motivate myself to try harder by dwelling on stupid things I did in the past

3. Thinking about what I did wrong in the past negatively affects my performance

4. I need to repeatedly think about things that I got wrong in order to avoid making mistakes in the future

5. Dwelling on my past mistakes represents a weakness of character

6. Repeatedly reviewing how I should have acted differently in the past shows that I care about the outcome

7. I will get depressed if I don't stop reviewing my self-critical thoughts

8. Not spending sufficient time thinking about past mistakes and failures will make me arrogant

9. Once I spot a thought about my self-worth, I have to analyse it

10. Reviewing past mistakes and failures can help me to understand things better

11. Having self-critical thoughts means that I am a weak person

12. Thinking about my self-worth (or lack of) helps me stay focused in the present

13. I have a hard time distancing myself from thoughts about not being good enough

14. I find it hard to stop thinking about my past mistakes once I have started

15. I tend to treat thoughts about my worth as facts - If I think them, they must be true
.05

.65

.72

.15

.64

.68

.24

.56

.55

$-.09$

.73

.61

.75

.73

$-.10$

.56

.79

.06

.86

$-.01$

.74

.06 
Table 2: Confirmatory factor analysis

\begin{tabular}{|c|c|c|c|c|c|}
\hline Model & $\chi^{2}$ & $\chi^{2 / \mathrm{df}}$ & CFI & TLI & RMSEA \\
\hline 1 (Orthogonal) & 416.10 & 4.62 & 0.75 & 0.71 & 0.121 \\
\hline $\begin{array}{c}2 \text { (Covaried latent } \\
\text { variables) }\end{array}$ & 240.79 & 2.71 & 0.88 & 0.86 & 0.083 \\
\hline $\begin{array}{l}3 \text { Covaried latent } \\
\text { variables with } 5 \\
\text { items removed }\end{array}$ & 56.25 & 1.65 & 0.97 & 0.96 & $0.052^{*}$ \\
\hline $\begin{array}{c}4 \text { (Single factor with } \\
10 \text { items) }\end{array}$ & 139.27 & 3.98 & 0.86 & 0.82 & 0.110 \\
\hline
\end{tabular}


Figure 1: Graphical representation of the optimal model of the MSCRQ.

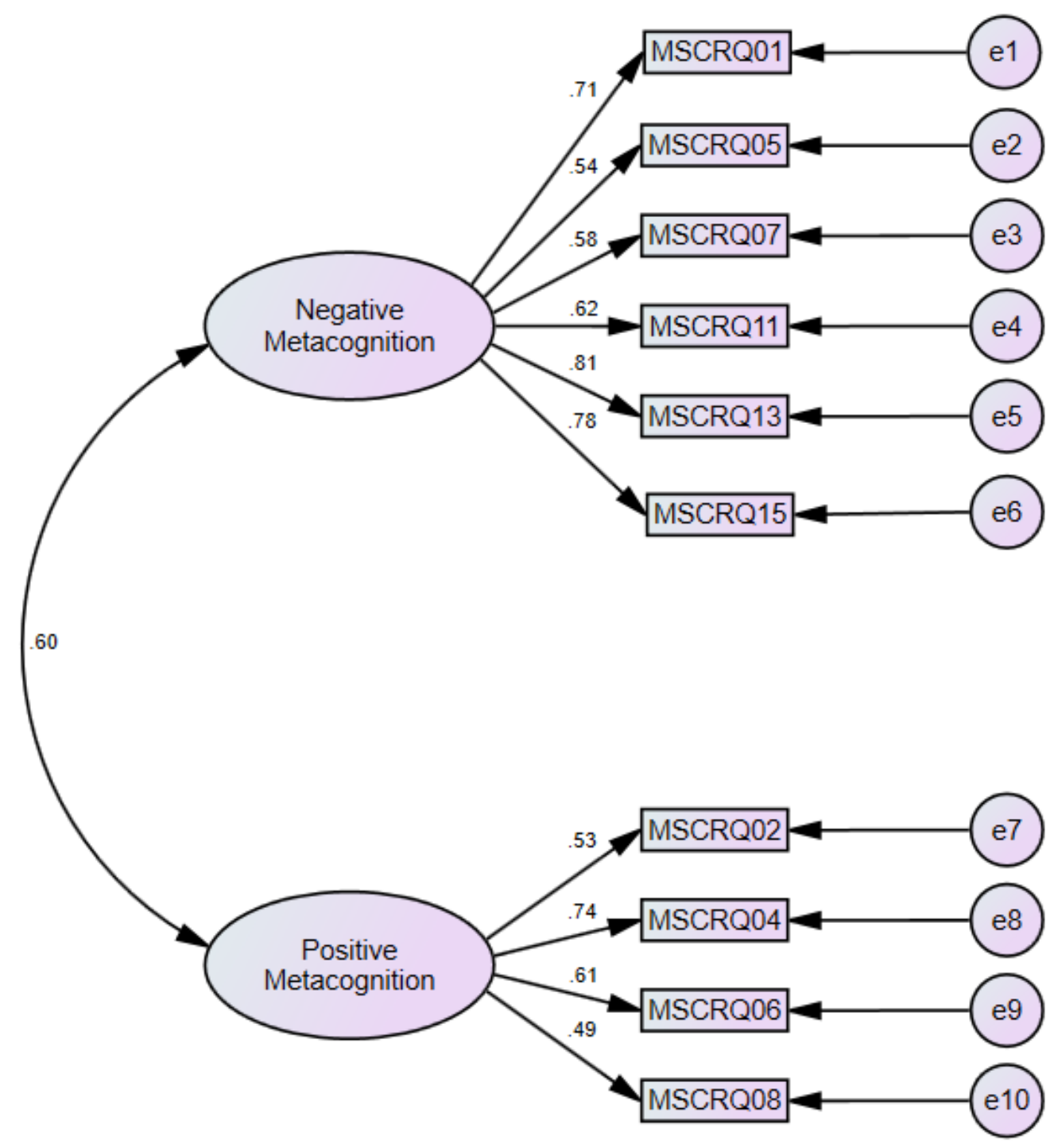


Table 3: Means, SDs, and ranges for all experimental variables.

\begin{tabular}{|c|c|c|c|}
\hline & Means & SD & Range \\
\hline 1. MSCRQ-N & 14.28 & 4.89 & 6 to 24 \\
\hline 2. MSCRQ-P & 8.25 & 2.88 & 4 to 16 \\
\hline 3. SCRS & 27.15 & 8.80 & 10 to 40 \\
\hline
\end{tabular}
4. SCRS-M
18.64
6.25
7 to 28

5. DEQ-SC6

27.64

9.71

6 to 42

6. RSES

25.41

7.32

10 to 40

7. MCQ (POS)

10.26

4.21

6 to 23

8. MCQ (NEG)

14.87

5.63

6 to 24

9. $\mathrm{MCQ}(\mathrm{CC})$

12.50

5.12

6 to 24

10. MCQ (NC)

11.91

4.30

6 to 24

11. MCQ (CSC)

15.84

4.52

6 to 24

12. DASS-D

15.12

6.70

7 to 28

13. DASS-A

11.88

4.81

7 to 28

14. DASS-S

15.84

5.54

7 to 27

15. DASS-T

42.84

15.41

21 to 80

Note: MSCRQ-N = Metacognitions about Self-Critical Rumination Scale (Negative); MSCRQ-P = Metacognitions about Self-Critical Rumination Scale (Positive); SCRS = Self-Critical Rumination Scale; SCRS$\mathrm{M}=$ Modified version of the Self-Critical Rumination Scale; DEQ-SC6 (Depressive Experiences Questionnaire Self-Criticism 6); RSES = Rosenberg Self-Esteem Scale; MCQ-30 (POS) = Metacognitive Questionnaire-30 (Positive); MCQ-30 (NEG) = Metacognitive Questionnaire-30 (Negative); MCQ-30 (CC) = Metacognitive Questionnaire-30 (Cognitive Confidence); MCQ-30 (NC) = Metacognitive Questionnaire-30 (Need for Control); MCQ-30 (CSC) = Metacognitive Questionnaire-30 (Cognitive Self-Consciousness); DASS-D = Depression, Anxiety Stress Scale-21 (Depression); DASS-A = Depression, Anxiety Stress Scale-21 (Anxiety); DASS-S = Depression, Anxiety Stress Scale-21 (Stress); DASS-T = Depression, Anxiety Stress Scale-21 (Total); $n=198-247$. 
Table 4: Correlation matrix of the study variables.

\begin{tabular}{|c|c|c|c|c|c|c|c|c|c|c|c|c|c|c|c|}
\hline & 1 & 2 & 3 & 4 & 5 & 6 & 7 & 8 & 9 & 10 & 11 & 12 & 13 & 14 & 15 \\
\hline 1. MSCRQ-N & & $.42 * *$ & $.84 * *$ & $.82 * *$ & $.66 * *$ & $-.74 * *$ & $.25 * *$ & $.70 * *$ & $.36 * *$ & $.70 * *$ & $.42 * *$ & $.66 * *$ & $.51 * *$ & $.67 * *$ & $.70 * *$ \\
\hline 2. MSCRQ-P & & & $.43 * *$ & $.43 * *$ & $.34 * *$ & $-.35 * *$ & $.50 * *$ & $.35 * *$ & .04 & $.39 * *$ & $.34 * *$ & $.27 * *$ & $.34 * *$ & $.36 * *$ & $.35 * *$ \\
\hline 3. SCRS & & & & $.99 * *$ & $.76^{* *}$ & $-.78 * *$ & $.29 * *$ & $.73 * *$ & $.29 * *$ & $.63 * *$ & $.46^{* *}$ & $.71 * *$ & $.53 * *$ & $.69 * *$ & $.73 * *$ \\
\hline 4. SCRS-M & & & & & $.77 * *$ & $-.79 * *$ & $.28 * *$ & $.71 * *$ & $.27 * *$ & $.63 * *$ & $.45 * *$ & $.72 * *$ & $.53 * *$ & $.69 * *$ & $.73 * *$ \\
\hline 5. DEQ-SC6 & & & & & & $-.65 * *$ & $.23 * *$ & $.60 * *$ & $.27 * *$ & $.53 * *$ & $.38 * *$ & $.62 * *$ & $.44 * *$ & $.60 * *$ & $.63 * *$ \\
\hline 6. RSES & & & & & & & $-.17 *$ & $-.63 * *$ & $-.27 * *$ & $-.53 * *$ & $-.30 * *$ & $-.72 * *$ & $-.54 * *$ & $-.63 * *$ & $-.71 * *$ \\
\hline 7. MCQ-30 (POS) & & & & & & & & $.33 * *$ & .07 & $.43 * *$ & $.28 * *$ & $.22 * *$ & $.21 * *$ & $.35 * *$ & $.29 * *$ \\
\hline 8. MCQ-30 (NEG) & & & & & & & & & $.30 * *$ & $.64 * *$ & $.51 * *$ & $.67 * *$ & $.59 * *$ & $.74 * *$ & $.74 * *$ \\
\hline 9. $\mathrm{MCQ}-30(\mathrm{CC})$ & & & & & & & & & & $.35 * *$ & $.17 *$ & $.33 * *$ & $.30 * *$ & $.28 * *$ & $.34 * *$ \\
\hline 10. MCQ-30 (NC) & & & & & & & & & & & $.52 * *$ & $.63 * *$ & $.45^{* *}$ & $.62 * *$ & $.64 * *$ \\
\hline 11. MCQ-30 (CSC) & & & & & & & & & & & & $.36 * *$ & $.33 * *$ & $.47 * *$ & $.42 * *$ \\
\hline 12. DASS-D & & & & & & & & & & & & & $.65 * *$ & $.79 * *$ & $.93 * *$ \\
\hline 13. DASS-A & & & & & & & & & & & & & & $.71 * *$ & $.83 * *$ \\
\hline 14. DASS-S & & & & & & & & & & & & & & & $.93 * *$ \\
\hline
\end{tabular}

$n=202-247 ; * \mathrm{p}<.05 ; * * \mathrm{p}<.01$

Note: MSCRQ-N = Metacognitions about Self-Critical Rumination Scale (Negative); MSCRQ-P = Metacognitions about Self-Critical Rumination Scale (Positive); SCRS = Self-Critical Rumination Scale; SCRS-M = Modified version of the Self-Critical Rumination Scale; DEQ-SC6 (Depressive Experiences Questionnaire Self-Criticism 6); RSES = Rosenberg Self-Esteem Scale; MCQ-30 (POS) = Metacognitive Questionnaire-30 (Positive); MCQ-30 (NEG) = Metacognitive Questionnaire-30 (Negative); MCQ-

30 (CC) = Metacognitive Questionnaire-30 (Cognitive Confidence); MCQ-30 (NC) = Metacognitive Questionnaire-30 (Need for Control); MCQ-30 (CSC) = Metacognitive Questionnaire-30 (Cognitive Self-Consciousness); DASS-D = Depression, Anxiety Stress Scale-21 (Depression); DASS-A = Depression, Anxiety Stress Scale-21 (Anxiety); DASS-S = Depression, Anxiety Stress Scale-21 (Stress); DASS-T = Depression, Anxiety Stress Scale-21 (Total); $n=202-247$. 
Table 5: Regression coefficients for the MSCRQ, accounting for affect, self-criticism, selfesteem and general metacognitions. Criterion variable: SCRS-M.

Coefficients $^{\text {a }}$

\begin{tabular}{|c|c|c|c|c|c|c|c|c|}
\hline \multirow{3}{*}{\multicolumn{2}{|c|}{ Model }} & \multicolumn{2}{|c|}{$\begin{array}{c}\text { Unstandardized } \\
\text { Coefficients } \\
\end{array}$} & \multirow{3}{*}{$\begin{array}{c}\text { Standardized } \\
\text { Coefficients } \\
\text { Beta }\end{array}$} & \multirow{4}{*}{$\begin{array}{c}\mathrm{t} \\
6.813\end{array}$} & \multirow{4}{*}{$\begin{array}{l}\text { Sig. } \\
.000\end{array}$} & \multicolumn{2}{|c|}{$\begin{array}{c}95.0 \% \text { Confidence } \\
\text { Interval for B } \\
\end{array}$} \\
\hline & & & & & & & \multirow{3}{*}{$\begin{array}{l}\text { Lower } \\
\text { Bound } \\
4.590\end{array}$} & \multirow{3}{*}{$\begin{array}{l}\text { Upper } \\
\text { Bound } \\
8.330\end{array}$} \\
\hline & & B & Std. Error & & & & & \\
\hline 1 & (Constant) & 6.460 & .948 & & & & & \\
\hline & DASS-D & .422 & .075 & .446 & 5.643 & .000 & .274 & .569 \\
\hline & DASS-A & -.070 & .095 & -.053 & -.734 & .464 & -.256 & .117 \\
\hline & DASS-S & .433 & .097 & .379 & 4.468 & .000 & .242 & .624 \\
\hline \multirow[t]{5}{*}{2} & (Constant) & 2.667 & .863 & & 3.091 & .002 & .965 & 4.369 \\
\hline & DASS-D & .234 & .064 & .247 & 3.661 & .000 & .108 & .360 \\
\hline & DASS-A & .025 & .078 & .019 & .325 & .745 & -.128 & .179 \\
\hline & DASS-S & .215 & .082 & .188 & 2.618 & .010 & .053 & .377 \\
\hline & DEQ-SC6 & .324 & .033 & .504 & 9.923 & .000 & .260 & .389 \\
\hline \multirow[t]{6}{*}{3} & (Constant) & 15.505 & 2.105 & & 7.365 & .000 & 11.352 & 19.657 \\
\hline & DASS-D & .095 & .062 & .101 & 1.549 & .123 & -.026 & .217 \\
\hline & DASS-A & -.002 & .071 & -.001 & -.022 & .982 & -.141 & .138 \\
\hline & DASS-S & .177 & .075 & .155 & 2.374 & .019 & .030 & .324 \\
\hline & DEQ-SC6 & .247 & .032 & .384 & 7.766 & .000 & .185 & .310 \\
\hline & RSES & -.307 & .047 & -.364 & -6.567 & .000 & -.399 & -.215 \\
\hline \multirow[t]{7}{*}{4} & (Constant) & 13.594 & 2.130 & & 6.381 & .000 & 9.392 & 17.797 \\
\hline & DASS-D & .124 & .061 & .131 & 2.043 & .042 & .004 & .243 \\
\hline & DASS-A & -.020 & .069 & -.016 & -.296 & .768 & -.157 & .116 \\
\hline & DASS-S & .140 & .074 & .123 & 1.911 & .057 & -.005 & .285 \\
\hline & DEQ-SC6 & .231 & .031 & .360 & 7.366 & .000 & .169 & .293 \\
\hline & RSES & -.289 & .046 & -.343 & -6.315 & .000 & -.380 & -.199 \\
\hline & MSCRQ-P & .272 & .082 & .129 & 3.334 & .001 & .111 & .434 \\
\hline \multirow[t]{8}{*}{5} & (Constant) & 8.705 & 2.050 & & 4.247 & .000 & 4.662 & 12.748 \\
\hline & DASS-D & .086 & .055 & .091 & 1.567 & .119 & -.022 & .194 \\
\hline & DASS-A & -.001 & .062 & .000 & -.009 & .993 & -.123 & .122 \\
\hline & DASS-S & .046 & .068 & .040 & .676 & .500 & -.088 & .179 \\
\hline & DEQ-SC6 & .182 & .029 & .282 & 6.220 & .000 & .124 & .239 \\
\hline & RSES & -.192 & .044 & -.227 & -4.386 & .000 & -.278 & -.105 \\
\hline & MSCRQ-P & .150 & .076 & .071 & 1.986 & .048 & .001 & .300 \\
\hline & MSCRQ-N & .463 & .068 & .359 & 6.759 & .000 & .328 & .597 \\
\hline
\end{tabular}




$\begin{array}{lrrrrrrr}\text { (Constant) } & 8.303 & 2.091 & & 3.971 & .000 & 4.178 & 12.429 \\ \text { DASS-D } & .092 & .056 & .098 & 1.653 & .100 & -.018 & .203 \\ \text { DASS-A } & .009 & .066 & .007 & .140 & .889 & -.120 & .139 \\ \text { DASS-S } & .002 & .072 & .001 & .023 & .982 & -.141 & .144 \\ \text { DEQ-SC6 } & .177 & .030 & .275 & 6.004 & .000 & .119 & .236 \\ \text { RSES } & -.187 & .044 & -.221 & -4.218 & .000 & -.274 & -.099 \\ \text { MSCRQ-P } & .131 & .086 & .062 & 1.526 & .129 & -.038 & .299 \\ \text { MSCRQ-N } & .472 & .077 & .366 & 6.142 & .000 & .320 & .623 \\ \text { MCQ-POS } & .007 & .060 & .004 & .111 & .912 & -.111 & .124 \\ \text { MCQ-NEG } & .081 & .060 & .073 & 1.362 & .175 & -.037 & .199 \\ \text { MCQ-CC } & -.043 & .044 & -.035 & -.975 & .331 & -.130 & .044 \\ \text { MCQ-NC } & -.073 & .075 & -.050 & -.964 & .336 & -.221 & .076 \\ \text { MCQ-CSC } & .065 & .054 & .047 & 1.210 & .228 & -.041 & .171\end{array}$

a. Dependent Variable: SCRS-M

Note: DASS-D = Depression, Anxiety Stress Scale-21 (Depression); DASS-A = Depression, Anxiety Stress Scale-21 (Anxiety); DASS-S = Depression, Anxiety Stress Scale-21 (Stress); DEQ-SC6 (Depressive Experiences Questionnaire Self-Criticism 6); RSES = Rosenberg Self-Esteem Scale; MCQ-30 (NEG) = Metacognitive Questionnaire-30 (Negative); MSCRQ-P = Metacognitions about Self-Critical Rumination Scale (Positive); MSCRQ-N = Metacognitions about Self-Critical Rumination Scale (Negative); SCRS-M = Modified version of the Self-Critical Rumination Scale; $n=202-247$. 
Table 6: Regression coefficients for the MSCRQ, accounting for self-criticism, self-esteem, self-critical rumination and general metacognitions. Criterion variable: DASS-T.

\section{Coefficients $^{\mathrm{a}}$}

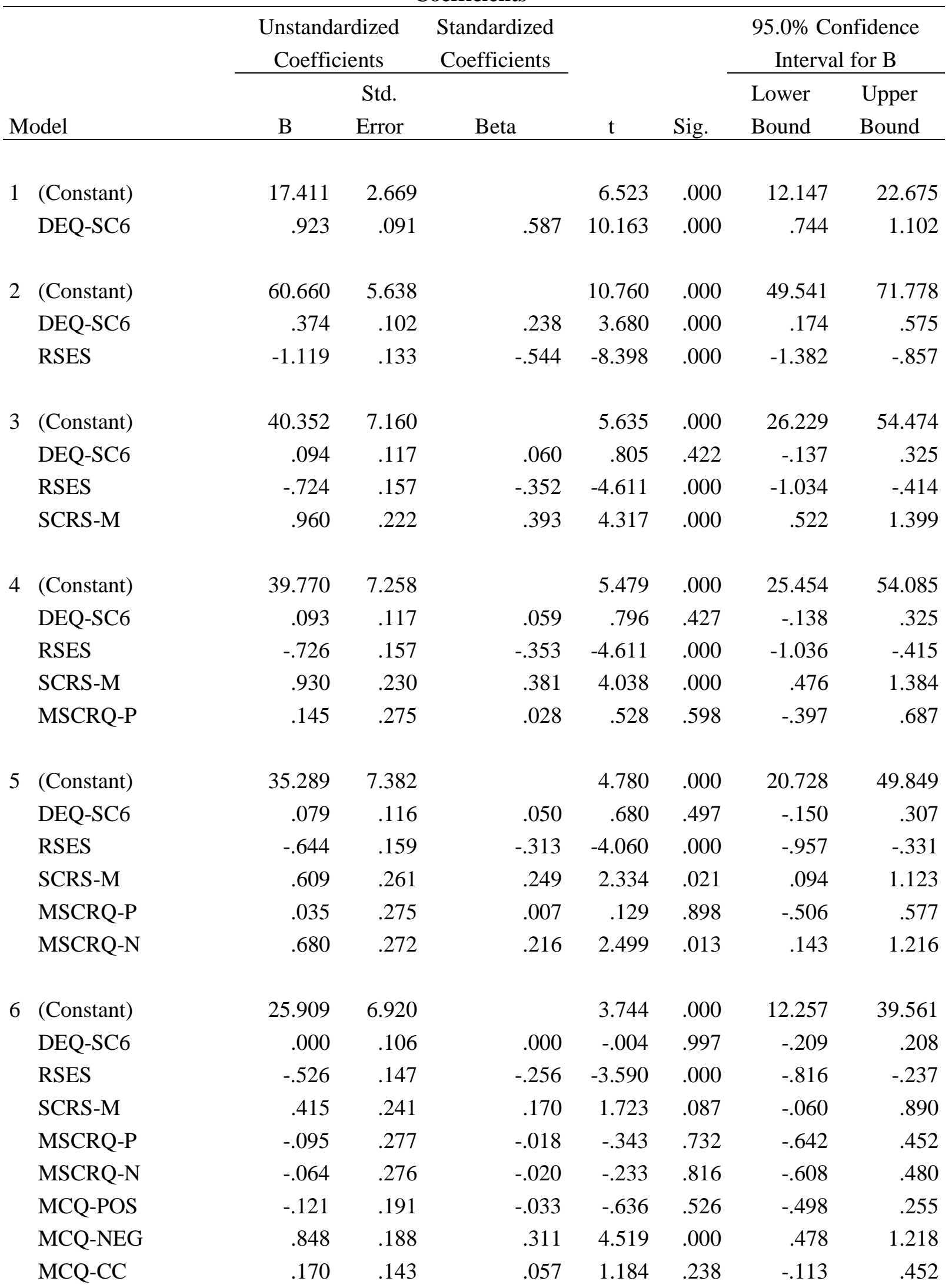


RUNNING HEAD: Metacognitions about Self-Critical Rumination Questionnaire

$\begin{array}{lrrrrrrr}\text { MCQ-NC } & .704 & .242 & .199 & 2.906 & .004 & .226 & 1.183 \\ \text { MCQ-CSC } & .130 & .177 & .038 & .737 & .462 & -.218 & .479\end{array}$

a. Dependent Variable: DASS-T

Note: DASS-T $=$ Depression, Anxiety Stress Scale-21 (Total); DEQ-SC6 (Depressive Experiences Questionnaire Self-Criticism 6); RSES = Rosenberg Self-Esteem Scale; SCRS-M = Modified version of the Self-Critical Rumination Scale; MSCRQ-P = Metacognitions about Self-Critical Rumination Scale (Positive); MSCRQ-N = Metacognitions about Self-Critical Rumination Scale (Negative); $n=202-247$. 